\title{
ARTIFICIAL AND REMOTE MANAGEMENT MODEL :INDUSTRY 6.0 INCREASED VIRTUAL AND ARTIFICIAL AUDIT
}

\author{
DOI: 10.17261/Pressacademia.2021.1441
}

PAP- V.13-2021(30)-p.114-115

\section{Murat Adil Salepcioglu}

İstanbul Aydın University, Faculty of Economics and Administrative Sciences, Departmant of Business Administration,İstanbul,Turkiye muratsalepcioglu@aydin.edu.tr, ORCID: 0000-0003-0280-9615

To cite this document

Salepcioglu, M.A., (2021). Artificial And Remote Management Model :Industry 6.0 Increased Virtual And Artificial Audit, PressAcademia Procedia (PAP), V.13, 114-115.

Permanent link to this document: http://doi.org/10.17261/Pressacademia.2021.1441

Copyright: Published by PressAcademia and limited licensed re-use rights only.

\begin{abstract}
Purpose- This research envisages conceptually demonstrating Industry 6.0, which can be a new model of governance, starting with the financial sector and addressing the issue, primarily based on the approach that business organizations will evolve into hybrid models.

Methodology- On the one hand, how a crypto asset created by using the blockchain (block-chain) ecosystem can be used by converting it into a kind of symbolic digital currency that will be created virtually through the process of accounting as a business investment tool and a financial instrument. On the other hand, a method to be developed will examine the prediction that economic balances can be achieved by using digital networks in the governance model to make businesses more resilient to financial fluctuations. In addition, based on the prediction that organizational sustainability and the most important global problem in economies is the management of risks, in order to establish the parameters of internal control, internal and external audit and corporate risk management of the governance process, using artificial intelligence and machine learning of the control mechanism, with logic in the project-oriented agile management approach of the accuracy and purpose-oriented audit process, how it can be involved in every stage of strategic decision-making processes and corporate governance practices. On the other hand, a review will be carried out by associating personnel empowerment and matrix organizations, organizational transformation and network structures, organizational agility and virtual organizations. In addition, the impact of organizational agility on quality will be thinned by addressing innovation and innovation-oriented components. At the same time, research will be supported by the study of estimating the impact of artificial neural networks and strategic management tools on business DNA. All findings of the research will be associated with each other and the research will be deepened. On the one hand, financial applications based on blockchain technologies, on the other hand, by estimating exchange rate ratios in financial markets, macroeconomic balances can be achieved as a result of corporate risk management through digital networks, deep learning and machine learning applications to make businesses more resilient to financial fluctuations and support corporate governance processes.the prediction that it will be examined. Since a modeling will be made using artificial intelligence and machine learning methods in these studies, the concept of artificial is used in this study. The concept of remote is also included because the control mechanism will be done by robo-processors in a way. In addition, since it is foreseen that virtual reality applications integrated with artificial intelligence can be discussed in the context of accelerating the decisionmaking process in the management process, it is aimed to establish a managerial decision-making model through audit-oriented processes on which the concept of Industry 6.0 is based, at the point where the increased corporate governance or artificial and remote governance process intersects with the increased virtual and artificial audit process.

Findings- When the research is completed, it will be discussed in detail. In the light of pilot studies, it is possible to say that the research results are positive.

Conclusion- With digital networks, an artificial remote governance model that will make decision-making processes in the business structure faster, more efficient and more efficient, and an industry 6.0 approach based on specific and scientific data will be introduced with an increased understanding of virtual and artificial control.
\end{abstract}

Keywords: Hybrid Organizations, Artificial and Remote Governance, Virtual and Artificial Control, Blockchain Technologies, Industry 6.0 JEL Codes: M10, M21, M42 


\section{YAPAY VE UZAKTAN YÖNETIŞiM MODELI : ENDÜSTRI 6.0 ARTIRILMIŞ SANAL VE YAPAY DENETIM}

\section{ÖZET}

Amaç- Bu araştırma, öncelikle işletme organizasyonlarının hibrit modellere evrileceği yaklaşımından hareket ederek, bu yapısal dönüşümün öncelikle finans sektöründen başlamak suretiyle konunun ele alınmasını sağlayacak şekilde, yeni bir yönetişim modeli olabilecek Endüstri 6.0'ı kavramsal olarak ortaya koymayı öngörmektedir.

Yöntem- Bir taraftan blockchain (block-zincir) ekosistemini kullanmak suretiyle oluşturulacak bir kripto varlığın, işletme yatırım aracı ve bir finansal enstrüman olarak muhasebeleştirilme süreci ile sanal olarak oluşturulacak bir tür sembolik dijital paraya dönüştürülerek, nasıl kullanılabileceği test edilecektir. Diğer taraftan geliştirilecek bir yöntemle işletmelerin finansal dalgalanmalara daha dayanıklı olmaları için yönetişim modelinde dijital ağlar kullanılarak ekonomik dengelerin sağlanabileceği öngörüsü irdelenecektir. Ayrıca ekonomilerde organizasyonel sürdürülebilirliğin ve en önemli küresel sorunun risklerin yönetilmesi olduğu öngörüsünden hareketle, yönetişim sürecinin iç kontrol, iç ve dış denetim ve kurumsal risk yönetimi parametrelerini ortaya koymak amacıyla, denetim mekanizmasının yapay zeka ve makine öğrenmesi kullanılarak, doğruluk ve amaç odaklı denetim sürecinin proje odaklı çevik yönetim yaklaşımındaki mantıkla, nasıl stratejik karar alma süreçlerinin her aşamasında ve kurumsal yönetişim uygulamaları içinde yer alabileceği araştırılacaktır. Diğer taraftan, personel güçlendirme ve matriks organizasyonlar, örgütsel dönüşüm ve network yapılar, örgütsel çeviklik ile sanal organizasyonlar ilişkilendirilerek bir inceleme yapılacaktır. Buna ilaveten örgütsel çevikliğin kalite üzerine etkisi ile inovasyon ve yenilik odaklı bileşenler ele alınarak incelecektir. Aynı zamanda yapay sinir ağları ile stratejik yönetim araçlarının İşletme DNA'sına etkisinin tahmin edilmesi çalışmasıyla da araştırma desteklenecektir. Araştırmadaki tüm bulgular birbiriyle ilişkilendirilerek araştırma derinleştirilecektir.Bir taraftan blokzincir teknolojilerine dayanan finansal uygulamalar, diğer taraftan finansal piyasalarda döviz kuru oranlarının tahmin edilmesi yoluyla, işletmelerin finansal dalgalanmalara daha dayanıklı olmaları ve kurumsal yönetişim süreçlerini destekleyecek şekilde kurumsal risk yönetimin dijital ağlar, derin öğrenme ve makine öğrenmesi uygulamalarıyla sağlanması sonucunda makro ekonomik dengelerin sağlanabileceği öngörüsü irdelenecektir. $\mathrm{Bu}$ çalışmalarda yapay zeka ve makine öğrenmesi metodları kullanılarak bir modelleme yapılacağından bu çalışmada yapay kavramı kullanılmaktadır. Denetim mekanizmasının bir bakıma robo-işlemciler tarafından yapılacak olması sebebiyle de uzaktan kavramına yer verilmiştir. Ayrıca, yönetim sürecinde karar verme sürecinin hızlandırılması bağlamında yapay zeka ile entegre sanal gerçeklik uygulamalarının da ele alınabileceği öngörüldüğünden, artırılmış kurumsal yönetişim veya yapay ve uzaktan yönetişim sürecinin, aynı zamanda artırılmış sanal ve yapay denetim süreci ile kesiştiği noktada, Endüstri 6.0 kavramının dayandığı, denetim (audit) odaklı süreçler üzerinden yönetsel karar alma modelinin oluşturulması hedeflenmektedir.

Bulgular- Araştırma tamamlandığında detaylandırılarak tartışılacaktır. Pilot çalışmalar ışığında araştırma sonuçlarının pozitif olduğunu söylemek mümkündür.

Sonuç- Dijital ağlarla işletme yapısındaki karar alma süreçlerinin daha hızlı, daha etkin ve daha verimli olmasını sağlayacak bir tür yapay uzaktan yönetişim modeli ile artırılmış sanal ve yapay denetim anlayışı ile kendine özgü ve bilimsel verilere dayanan Endüstri 6.0 yaklaşımı ortaya konulmuş olacaktır.

Anahtar Kelimeler: Hibrit Organizasyonlar, Yapay ve Uzaktan Yönetişim, Sanal Ve Yapay Denetim, Blok-Zincir Teknolojileri, Endüstri 6.0 JEL Kodları: M10, M21, M42

\section{KAYNAKÇA}

Avcı, O . (2021). Vergi tahsilatında yapay zekânın kullanımı ve önemi . Eskişehir Osmangazi Üniversitesi Sosyal Bilimler Dergisi , 22 (1) , $51-63$. DOI: $10.17494 /$ ogusbd.952730

Aygün, S , Sezgin, O . (2021). The methods and tools used by managers in theır strategıc decısıon makıng processes . Stratejik ve Sosyal Araştırmalar Dergisi , 5 (2) , 281-293 . DOI: 10.30692/sisad.914978

Canbay, P , Demircioğlu, Z . (2021). Endüstri 5.0'a doğru: zeki otonom sistemlerde etik ve ahlaki sorumluluklar . AJIT-e: Bilişim Teknolojileri Online Dergisi , 12 (45) , 106-123 . DOI: 10.5824/ajite.2021.02.006.

Dikilitaş, Y , Toka, K , Sayar, A . (2021). Current research areas in blockchain . Avrupa Bilim ve Teknoloji Dergisi, Ejosat Special Issue 2021 (HORA) , 488-492 . DOI: 10.31590/ejosat.977320

İmamoğlu, S , İnce, H , Türkcan, H . (2021). Endüstri 4.0 uygulamalarının örgütsel çeviklik üzerindeki etkisi: kavramsal bir çalışma. Atatürk Üniversitesi İktisadi ve İdari Bilimler Dergisi , 35 (1) , 103-124 . DOI: 10.16951/atauniiibd.740820

Mccarthy, J. (2007). What is artificial intelligence? Basic Questions. Computer Science Department, Stanford University. https://stanford. io/2ISo373.

Mccarthy, J., Minsky, M., Rochester, N., \&Shannon, C. E. (2006). A Proposal for the Dartmouth Summer Research Project on Artifcial Intelligence. Al Magazine, 27.

Mokyr, J., Vickers, C., \& Ziebarth, N. L. (2015). The history of technological anxiety and the future of economic growth: Is this time different? Journal of Economic Perspectives, 29(3), 31-50. https://doi.org/10.1257/jep.29.3.31

Ozguner, M . (2021). Çevik üretimin işletme performansına etkisinde inovasyonun aracı rolü . Oltu Beşeri ve Sosyal Bilimler Fakültesi Dergisi, 2(1) , 82-100 . Retrieved from https://dergipark.org.tr/en/pub/oltu/issue/60221/820383

Yılmaz, A. (2019). Yapay Zeka. İnkılap Kitabevi. 